\title{
Application research of electro-hydraulic proportional amplifier
}

\author{
Tan Changke \\ College of Mechanical Engineering \\ Xijing University \\ Xi'an, China \\ e-mail: 995965262@qq.com \\ Tong Chonglou \\ College of Mechanical Engineering \\ Xijing University \\ Xi'an, China \\ e-mail: 1205802724@qq.com
}

\author{
Zhai Xiaoshuai \\ College of Mechanical Engineering \\ Xijing University \\ Xi'an, China \\ e-mail: 815462986@qq.com \\ Zhang Yu \\ College of Mechanical Engineering \\ Xijing University \\ Xi'an, China \\ e-mail: 258522961@qq.com
}

\begin{abstract}
Closed-loop control or open-loop control of proportional valve can be completed when the drive current of electro-hydraulic proportional valve is provided by electro-hydraulic proportional amplifier. The control performance of proportional valve can be directly decided by the electro-hydraulic proportional amplifier. Electrohydraulic proportional control amplifier is an important part of the control system of electro-hydraulic proportional. so the application research of electro-hydraulic proportional control amplifier has an important value and significance. In this article, development and composition of proportional control amplifier are simply introduced; Working principle of proportional control amplifier is discussed; Working principle of electro-hydraulic proportional amplifier on control circuit and driver circuit is analyzed; Working principle of the key components of the electro-hydraulic proportional control amplifier are described, and the application foreground of electro-hydraulic proportional amplifier is prospected. Combined with some new technologies of PID control, the state feedback control, adaptive control, variable structure control and fuzzy logic control, it is pointed out that electro-hydraulic proportional amplifier will be in this direction of state feedback control, adaptive control, variable structure control and fuzzy logic control, etc.
\end{abstract}

Keywords-electro-hydraulic proportional amplifier; proportional valves; PWM; sensor; integrated circuit;

The function of electro-hydraulic proportional amplifier is to provide a specific performance of current for proportion of magnet, and electro-hydraulic proportional amplifier is an electronic device which is for open loop or closed loop control for electro-hydraulic proportional valve and electro-hydraulic proportional control system. Electro-hydraulic proportional amplifier is an important part of the element or system of electrohydraulic proportional control. Form of electro-hydraulic proportional amplifier is analogue and PWM mode [1]. The output current analog proportional amplifier is continuous, and the amplifier tube is work in the linear region. The amplifier tube of PWM is work in switch state. Combined with some new technologies of PID control In this article, the state feedback control, adaptive control, variable structure control and fuzzy logic control, it is pointed out that electro-hydraulic proportional amplifier will be in this direction of state feedback control, adaptive control, variable structure control and fuzzy logic control, etc.

\section{ELECTRO-HYDRAULIC PROPORTIONAL AMPLIFIER}

\section{A. Development of the proportional control amplifier}

Proportional control system has some advantages, such as large output power, power transmission is convenient, low cost, etc. Therefore proportional control system has wide application in various industrial fields [2]. Proportional control amplifier (hereinafter referred to as PCA) is an important component unit of the component of electro-hydraulic proportional system. Function of PCA is to provide current of specific performance for proportional electromagnet or other electrical machinery converter, and PCA is an electronic device of open loop or closed loop regulation for the electro-hydraulic proportional valve and electro-hydraulic proportional control system. Technology of electro-hydraulic proportional control is widely applied in all kinds of transmission system and control system, the main reason is that PCA is flexible [3].

Development of the proportional control amplifier can be divided into three stages:

At first, the design of PCA is to simulate constant pressure type. The design of control performance is poor, and the open loop control is more. Then design of the PCA is constant flow. The constant flow can restrain the influence of thermal characteristics, and the constant flow dynamic performance is better than that of constant pressure type. So the constant pressure type is replaced by the constant flow.

(2) The proportion control amplifier was divided into analog and switch type in the early eighty s. Analog power amplifier tube work in linear power amplifier. Power consumption of this tube is large, temperature is high. So 
the utilization of electric power is low [4]. The reliability of the control amplifier is affected, and it is limited in high temperature environment, at the same time the cost of the amplifier is increased. The power consumption of switch power amplifier tube is small, temperature rise is also low. Switch type is better than that of analog for reduce consumption. So the PWM control technology of low switching frequency is widely used in electro-hydraulic proportional control.

(3)After the eighty s, with the development of largescale integrated circuits, the discrete component is gradually replaced by the integrated circuit which the reliability and cost performance are better than that of early discrete component consisting of proportional amplifier. In order to solve the problem of an independent regulation of frequency and amplitude of low frequency pulse width modulation component of flutter, and switch type amplifier is improved [5]. Using high frequency pulse width modulation technology, the modulation frequency can reach a few KHZ. At the same time, the use of fast power drive circuit, electromagnetic coil discharge time is improving for the traditional drive circuit, and charging rate and discharge rate are equal. Reducing the time of transition, to improve the dynamic response of the proportional solenoid, the dynamic characteristic of proportional valve is improved.

\section{B. Composition and classification of PCA}

PCA is an electronic control device which can be plastic, computing and power amplification for control signal. The basic requirement of proportional control amplifier is able to produce the right effective control signals. In order to overcome the influence of dead area, and amplifier should have the function that the initial current is adjustable. To reduce the influence of hysteresis, the output current of amplifier should contain a flutter circuit [6]. If the amplifier adopts the control mode of PWM, the flutter signal generator can be omitted. To reduce the impact of the transition, the step is automatically generating ramp signal which the speed is adjustable [7]. The basic component of proportional control amplifier is shown in Fig .1. It includes the generated signal, preamplifier, control circuit, power amplifier, etc.

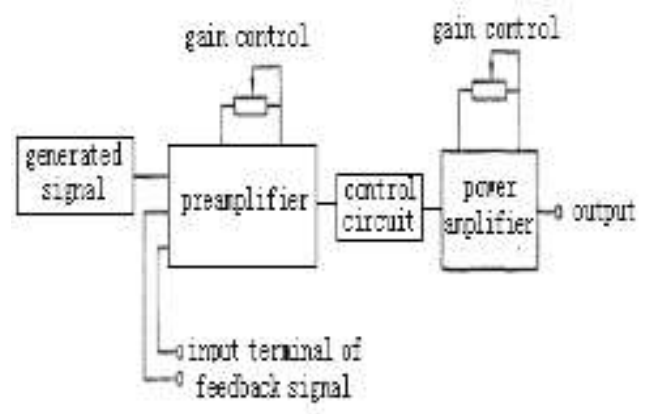

Figure.1 Basic component of PCA

Classification according to the use generally can be divided into general and special proportion amplifier. The proportion of the general amplifier is divided into force control and position control, single channel and dual channel, etc. When the proportion control amplifier was classified according to the use, the proportional amplifier is generally divided into general and special. The proportion of general amplifier is divided into force control and position control, single channel and dual channel, etc.

\section{COMPOSITION AND WORKING PRINCIPLE OF EPCA}

\section{A. Composition of electro-hydraulic EPCA}

Electro-hydraulic proportional control amplifier is referred to as EPCA. The component of EPCA is made simple introduction when AVS - D4 - S1-1 being as an example.EPCA of AVS - D4 - S1-10 is composed of some basic units, such as generating circuit about the control signal, the signal processing circuit, control circuit, power driving circuit, measuring amplifier amplification circuit, power amplifier circuit, etc[8]. The amplifier control circuit, power drive circuit is the most important part of the proportional control amplifier.

The specific function of each component of EPCA as shown below:

(1) The signal processing circuit: the input signal is the corresponding processing, to adapt to a variety of different control object and requirements of working condition.

(2) The amplifier control circuit: it is an important circuit of EPCA, and it is the main component unit of closed-loop electro-hydraulic proportional control system. It is the function of improving the quality of the static and dynamic quality of proportional valve of electro-hydraulic proportional control system. Amplifier to realize control adopts upc1009 integrated circuit which is based on PWM control technology.

(3) Power driver circuit: it is the most important part of EPCA. EPCA steady performance and dynamic performance are decided by power driver circuit [9]. In order to achieve the power drive, amplifier adopts integrated circuit which is two.

(4) Measuring amplifier circuit: the measuring amplifier circuit of EPCA which match the displacement sensor that mounted on the valve core of proportional valve. Sensor feedback signal is amplified processing through measuring amplifier circuit, so as to realize the closed loop of electro-hydraulic proportional control system.

(5) Amplifier circuit: The role of amplifier circuit to provide the required power supply for the control circuit, and it is to ensure the normal operation of the amplifier.

\section{B. Working principle of EPCA}

The working principle of EPCA as shown in Fig .2.

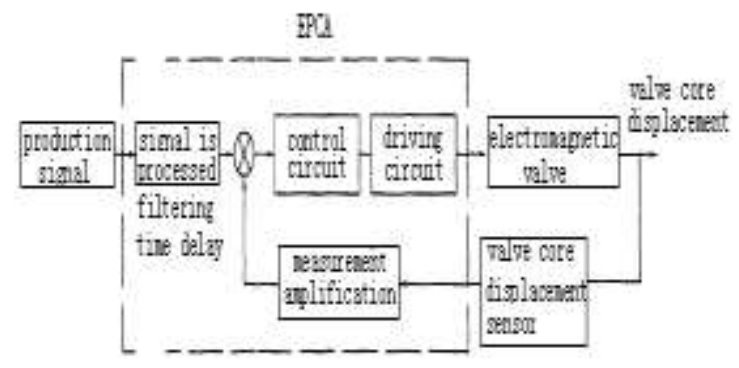

Figure. 2 working principle of EPCA 
The control signal is generated by a computer which is $\mathrm{U}_{0}$. The feedback signal of valve core displacement sensor is $\mathrm{U}_{1}$. After comparing $\mathrm{U}_{0}$ and $\mathrm{U}_{1}$, comparison results input control circuit after processing, and signal into the IR2110 bridge drive circuit by PWM control circuit. The electrical signal by the drive input proportional electromagnetic valve, to control valve core displacement in order to realize the system control of the actuator.

\section{CONTROL CIRCUIT AND DRIVE CIRCUIT OF EPCA}

Control circuit and drive circuit of EPCA is one of the most important part about proportional control amplifier. The following control and drive circuit principle of work and related chips will be introduced.

\section{A. Control circuit and drive circuit of EPCA}

EPCA working principle of control circuit and drive circuit is shown in Fig .3.

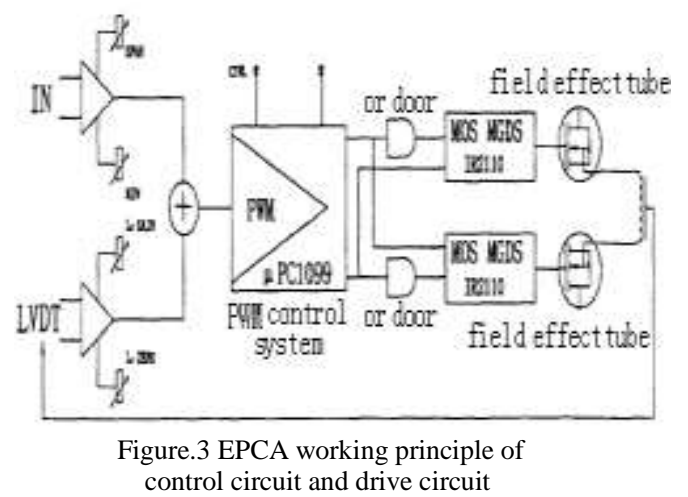

The Fig .3 shows: the control signal is input to the control circuit after processing by signal processing module, and the feedback signal of valve core displacement sensor input to control circuit after measuring amplifier module place. In the control circuit, the control signal is designed, and the feedback signal adjust circuit is designed, and the adjustment of proportional amplifier set data is implemented. The control signal and feedback signal into the system of PWM after the error of the comparator. The PWM control chip of control circuit adopts UPCI099 integrated circuit. In the control circuit, the current size is mainly adopts the pulse width modulation method. After a PWM control system, output signal into the IR 2110 bridge drive. Full bridge circuit is designed by IR2110, and the automatic control of electro-hydraulic proportional valve is realized [10].

By Fig . 3 shows: the control signal is signal processing module for processing after the input to the control circuit, at the same time, the feedback signal of the valve core displacement sensor by measuring amplifier module input to the control circuit. In the control circuit design of the control signal, feedback signal adjusting circuit, realize the proportional amplifier set point adjustment. Enter the PWM control signal, feedback signal control system after the error of the comparator. The control circuit of PWM control chip adopts UPCI099 integrated circuit. In the control circuit, the current size is mainly adopts the pulse width modulation method. The output signal into IR2110 driver after PWM control system of the whole bridge. Full bridge circuits are designed by IR 2110 , nearly to achieve automatic control of electro-hydraulic proportional valve.

\section{B. Parts of control and drive circuit}

\section{(1) UPC1099}

In EPCA circuit, the control circuit of PWM is adopted. Control chip of control circuit of PWM is UPG1099. As shown in Fig .4, the chip components of UPC1099 include: the sawtooth wave generator, controller, PWM comparator, triggers, error amplifier, reference voltage source and two driving triode.

(2)Gate drive integrated circuit of 1R2110

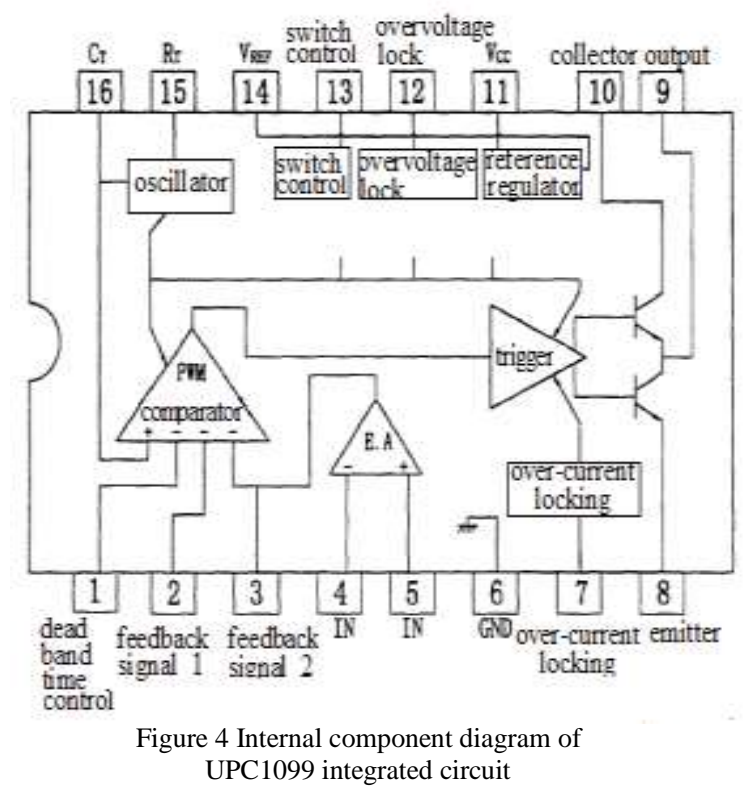

IR2110 gate drive integrated circuit by the international rectifier company which will be concentrated in a highperformance packaging that most of the power is used to drive low side and high side power. The switch speed that Is provided by IR2110 Is quick, and the power consumption that Is provided by IR 2110 is very low. In the case of bootstrap mode, IR2110 driver can work in the application of the circuit of $10 \mathrm{hz} \sim 100000 \mathrm{hz}$. In Fig .5, IR211 chip is composed of high power transistor driver stage, the low end of the power transistor driver stage, level converter and input logic circuit.IR2110 driver chip circuit diagram as shown in Fig .5

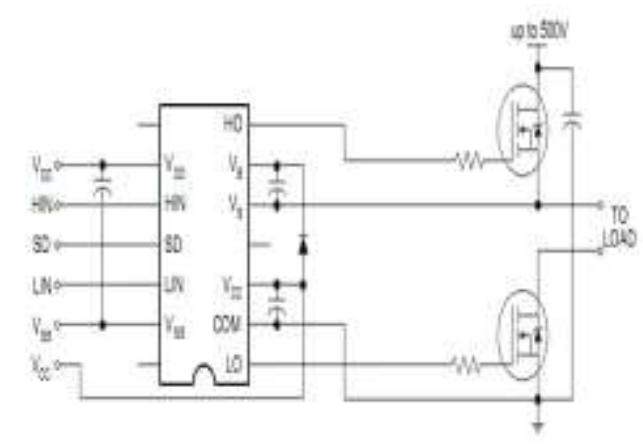

Figure .5 IR2110 driver chip circuit diagram 


\section{APPLICATION PROSPECT OF PCA}

\section{A. Analysis of current application of PCA}

Common electro-hydraulic proportional valve is electrical - liquid transition device that it can be get by the above analysis, and its driver is proportional electromagnet. But it has many shortcomings, such as the volume and inertia of moving parts are big, the support part is more, the frictional force is larger, linearity is poor, etc. Therefore, general electro-hydraulic proportional control equipment cannot satisfy some advantages, such as the control speed of hydraulic is high, the control precision is high, the flow is big, the cost is low, and the pollution is small, and so on [11]. In order to overcome the above shortcomings, a kind of ultra-high speed electro-hydraulic proportional control device is developed in recent years. Ultra-high speed electro-hydraulic proportional control amplifier has some advantages, such as the speed of the system is high, the precision of the system is high, the flow is big, cost is low, pollution is small, and so on.

\section{B. Application prospect}

Performance of the electro-hydraulic proportional amplifier be improved has great significance [12]. These indicators are frequency response, linearity, load capacity, etc. The improvement of these measures will help to enhance the overall characteristics of the electrohydraulic proportional amplifier, and this also will be the development trend of electro-hydraulic proportional control technology. At the same time the improvement of the performance of the electro-hydraulic proportional control also depends on the new control technology, such as PID control, the state feedback control, adaptive control, variable structure control, fuzzy logic control, etc.

\section{CONCLUSIONS}

Electro-hydraulic proportional amplifier has begun to rapid development in the direction of digitization. The combination of hydraulic technology, electronic technology and control technology is increasingly close, and the performance of the electro-hydraulic proportional control amplifier has been a certain degree of ascension.
Electro-hydraulic proportional control amplifier will combine to some new technology for develop, such as the state feedback control, adaptive control, variable structure control and fuzzy logic control, etc. Electro-hydraulic proportional control amplifier will have greater breakthrough in electronic devices, control strategy, software and materials. Therefore, the electro-hydraulic proportional control amplifier will achieve the development of more and more widely in various engineering fields.

\section{REFERENCES}

[1] Jiang Bo, XiaoXinYuan, YanChaoYong. Electro-hydraulic control technology of modern engineering machinery [M]. Chongqing: Chongqing university press, 2011.

[2] Wu Weitao. Electro-hydraulic proportional control technology review [J]. Power supply technology. 2013 (8), pp.405.

[3] http://www.neatorobotics.com/

[4] Astrom K J, Hagglund T.P ID controlers: theory, the design and tuning, Research Triangle Park, American:Instrument Society of American, 2010

[5] Sun Xue. Experiment teaching of electro-hydraulic proportional amplifier [J]. Journal of liaoning university of science and technology. 2011 (6), pp.2011-609.

[6] Yi Menglin, Cao Shuping, Liu Yinshui. Electro-hydraulic control technology $[\mathrm{M}]$. Huazhong: Huazhong university of science and technology press, 2010.

[7] $\mathrm{Xu}$ Zhenbao. Electro-hydraulic proportional control technology research [M].Taishan: Taishan vocational and technical college, 2010

[8] Zhang xin, Xu Kun peng. Development and application of electrohydraulic proportional control technology $[\mathrm{J}]$. Journal of association for science and technology. 2011 (10),pp.36 -37.

[9] Liu Heping, Yan Liping. Principle and application of controller of digital signal $[\mathrm{M}]$. Beijing: Beijing aerospace University press. 2011.07

[10] Li Yunzhuang, GeYiyuan. Hydraulic components and system design $[\mathrm{M}]$. Hubei: Hua Zhong university of science and technology press.2010.

[11] Wu Xiaoling, Yang Daguang. Research and application of hydraulic cylinder test-bed electro-hydraulic control system [J]. Mechanical and electrical engineering.2010 (5), pp.5354

[12] Wang Caixia. Application technology of hydraulic transmission[J] Journal of new technology. 2010 (5),pp. 69-70. 